\title{
Heat and moisture transport in porous materials involving cyclic wetting and drying
}

\author{
R. Černý, J. Maděra, J. Kočí \& E. Vejmelková \\ Czech Technical University in Prague, Faculty of Civil Engineering, \\ Department of Materials Engineering and Chemistry, Czech Republic
}

\begin{abstract}
Computational modeling of coupled heat and moisture transport in porous building materials with hysteretic moisture transport and storage parameters in the conditions of difference climate is presented in the paper. A diffusion-type model is used for the description of coupled heat and moisture transport. An empirical procedure is chosen to describe the path between the transport and storage parameters corresponding to wetting and drying. In a practical example of computer simulation, a concrete wall provided with exterior thermal insulation is analyzed. Computational results reveal very significant differences in moisture and relative humidity profiles calculated using the model with hysteretic parameters and without hysteresis. As the differences are on dangerous side from the hygrothermal point of view, the application of hysteretic moisture transport and storage parameters in computational models can be considered as quite important for service life analyses of multi-layered systems of building materials.
\end{abstract}

Keywords: moisture transport, hysteresis, computer simulation.

\section{Introduction}

Heat and moisture transport calculations are quite common in service life analyses of multi-layered systems of building materials. They make it possible to identify potential weak points in building envelopes from the hygro-thermal point of view, thus allow to react to possible danger in time and prevent excessive damage caused for instance by accumulation of liquid water in specific parts of a structure. Although it is known for years that moisture transport and storage parameters of many porous materials may exhibit considerable hysteresis, most of the calculations are still performed with parameters measured 
during the adsorption phase which is an apparent consequence of difficulties the experimentalists face in the measurements of some parameters in desorption phase.

In this paper, the effect of hysteresis of moisture transport and storage parameters on calculated moisture and relative humidity fields is investigated for a characteristic case of concrete wall with exterior thermal insulation, and the possible consequences of neglecting hysteresis of these parameters for service life calculations are analyzed.

\section{Mathematical model}

The diffusion model proposed by Künzel [1] was used for description of coupled heat and moisture transport. The heat and moisture balance equations were formulated in the form

$$
\begin{gathered}
\frac{\mathrm{d} H}{\mathrm{~d} T} \frac{\partial T}{\partial t}=\operatorname{div}(\lambda \operatorname{grad} T)+L_{v} \operatorname{div}\left[\delta_{\mathrm{p}} \operatorname{grad}\left(\varphi \mathrm{p}_{\mathrm{s}}\right)\right], \\
\frac{\partial \rho_{v}}{\partial \varphi} \frac{\partial \varphi}{\partial t}=\operatorname{div}\left[D_{\varphi} \operatorname{grad} \varphi+\delta_{p} \operatorname{grad}\left(\varphi p_{s}\right)\right],
\end{gathered}
$$

where $H$ is the enthalpy density, $L_{v}$ heat of evaporation, $\lambda$ thermal conductivity, $T$ temperature, $\rho_{v}$ partial density of moisture, $\varphi$ relative humidity, $\delta_{p}$ permeability of water vapor, $p_{s}$ partial pressure of saturated water vapor,

$$
D_{\varphi}=D_{w} \frac{\mathrm{d} \rho_{v}}{\mathrm{~d} \varphi}
$$

is the liquid water transport coefficient, $D_{W}$ capillary transport coefficient (moisture diffusivity).

The inclusion of cyclic wetting and drying processes into the model was done using different moisture transport and storage parameters functions in wetting and drying phase and calculating the path between the parameter functions corresponding to wetting and drying in every time step.

For describing the path between the adsorption and desorption isotherms an empirical procedure was chosen which follows Pedersen's hysteretic model [2]. The actual value of moisture content, $w$, is determined using equation

$$
w=w_{p}+\xi\left(\varphi_{a}-\varphi_{p}\right)
$$

where $\varphi_{a}$ is the actual value of relative humidity and $\varphi_{p}$ the value of relative humidity from previous calculation step, $\xi$ is the slope of the hysteretic parameter which is calculated as

$$
\xi=\frac{a_{d}\left(w_{p}-w_{a}\right)^{2} \xi_{d}+a_{a}\left(w_{p}-w_{d}\right)^{2} \xi_{a}}{\left(w_{d}-w_{a}\right)^{2}}
$$

$w_{p}$ is the value of moisture content from previous calculation step, $w_{a}$ and $w_{d}$ are values of moisture content for adsorption and desorption cycles, $\xi_{a}$ and $\xi_{d}$ the values for tangent adsorption and desorption in the points $w_{a}$ and $w_{d}, a_{a}$ and $a_{d}$ 
the correction coefficients. An example of the calculation of the path between the adsorption and desorption isotherms is given in Figure 1.

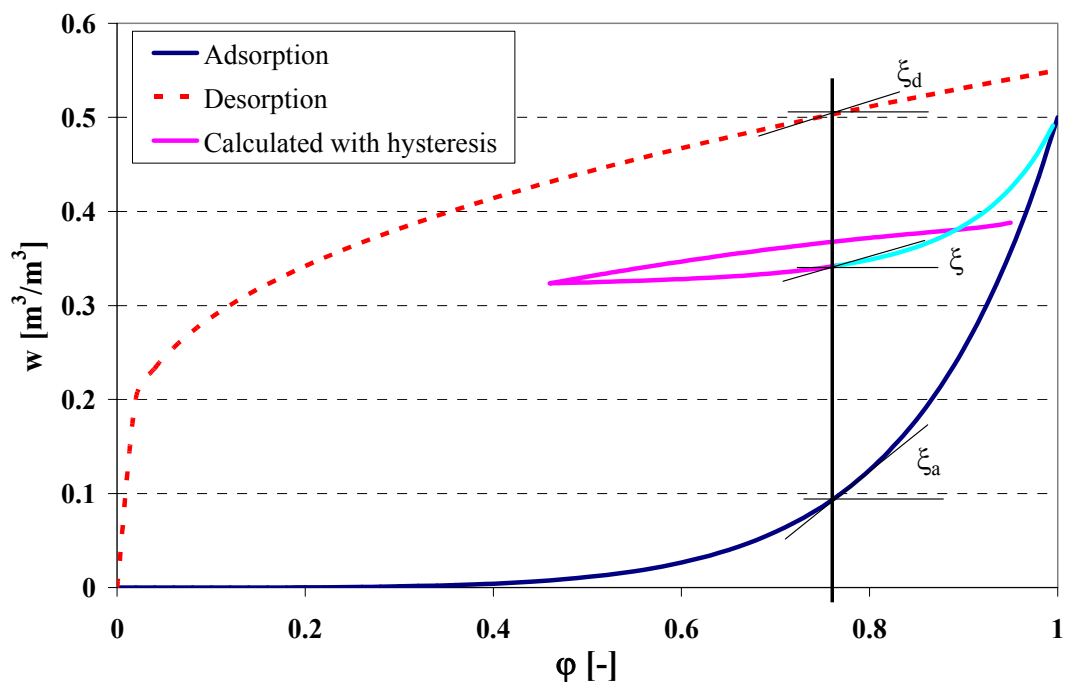

Figure 1: Example of application of hysteresis to sorption isotherms during drying and wetting cycles.

In the case of moisture diffusivity, a modification of (5) was necessary in order to express the hysteretic effect in more accurate way. The modified equation can be expressed as

$$
\xi=\frac{a_{d}\left(\ln \kappa_{p}-\ln \kappa_{a}\right)^{2} \ln \xi_{d}+a_{a}\left(\ln \kappa_{p}-\ln \kappa_{d}\right)^{2} \ln \xi_{a}}{\left(\ln \kappa_{d}-\ln \kappa_{a}\right)^{2}},
$$

where $\kappa_{p}$ is the value of moisture diffusivity from previous calculation step.

\section{Materials and building envelope}

A simplified building envelope system was chosen for the investigation of the effect of hysteresis on the calculated moisture and relative humidity fields. The load-bearing structure was made of high performance concrete containing metakaolin $(600 \mathrm{~mm})$. Mineral wool $(140 \mathrm{~mm})$ was used as exterior thermal insulation. Lime-cement plaster $(10 \mathrm{~mm})$ was on both exterior and interior side. The building envelope was exposed from inside to constant conditions (temperature equal to $21^{\circ} \mathrm{C}$ and relative humidity equal to $55 \%$ ) and from outside to climatic conditions corresponding to the reference year for Prague (Fig. 2). 
INSIDE

Constant
temperature
$\mathrm{T}=21{ }^{\circ} \mathrm{C}$

Constant
relative
humidity
$\varphi=55 \%$

\section{OUTSIDE}

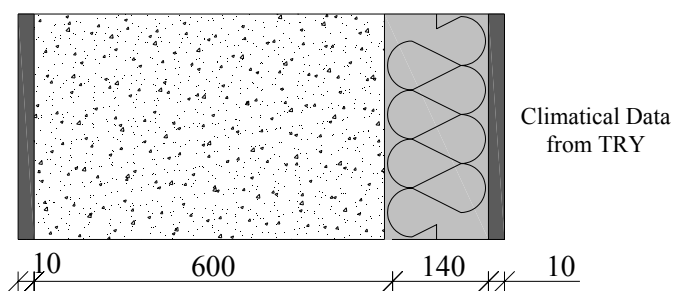

Figure 2: Scheme of the studied envelope including boundary conditions.

Table 1: Basic parameters of materials of the studied building envelope.

\begin{tabular}{lccccc}
\hline Parameter & Unit & HPCM & MW & LCP & LPMH \\
\hline$\rho$ & {$\left[\mathrm{kg} / \mathrm{m}^{3}\right]$} & 2366 & 170 & 1550 & 1745 \\
$\mathrm{w}_{\text {hyg }}$ & {$\left[\mathrm{m}^{3} / \mathrm{m}^{3}\right]$} & 0.107 & 0.0073 & 0.03 & 0.024 \\
$\mathrm{w}_{\text {sat }}$ & {$\left[\mathrm{m}^{3} / \mathrm{m}^{3}\right]$} & 0.13 & 0.89 & 0.40 & 0.33 \\
$\lambda_{\text {dry }}$ & {$[\mathrm{W} / \mathrm{mK}]$} & 1.56 & 0.055 & 0.70 & 0.84 \\
$\lambda_{\text {sat }}$ & {$[\mathrm{W} / \mathrm{mK}]$} & 2.09 & 1.20 & 2.40 & 2.40 \\
$\kappa$ & {$\left[\mathrm{m}^{2} / \mathrm{s}\right]$} & see Fig. 4 & $5.1 \mathrm{E}-10$ & $7.3 \mathrm{E}-7$ & $3.9 \mathrm{E}-8$ \\
& & & $\mathrm{e}^{3.12 \mathrm{w}}$ & $\mathrm{e}^{3.2 \mathrm{w}}$ & \\
$\mathrm{c}$ & {$[\mathrm{J} / \mathrm{kgK}]$} & 730 & 1000 & 1200 & 610 \\
$\mu$ & {$[-]$} & 21 & 45 & 7 & 13 \\
\hline
\end{tabular}

The initial conditions were chosen as follows: relative humidity $89 \%$ and constant temperature profile equal to $21^{\circ} \mathrm{C}$.

The basic material parameters of concrete (HPCM), mineral wool (MW), lime-cement plaster (LCP) and hydrophobized lime plaster modified by metakaolin (LPMH) are shown in Table 1 where the following symbols were used: $\rho$ - bulk density, $c$ - specific heat capacity, $\mu$ - water vapor diffusion resistance factor, $\lambda_{d r y}$ - thermal conductivity in dry conditions, $\lambda_{\text {sat }}-$ thermal conductivity in water saturated conditions, $\kappa$ - moisture diffusivity, $w_{\text {hyg }}-$ hygroscopic moisture content by volume, $w_{\text {sat }}$ - saturated moisture content by volume. Fig. 3 presents the sorption isotherms of concrete used in the simulations. The data were obtained by experiments performed at the Department of Materials Engineering and Chemistry, Faculty of Civil Engineering, Czech Technical University in Prague [3, 4].

Fig. 4 presents the moisture diffusivity of concrete. Moisture diffusivity vs. moisture function for adsorption was derived according to (7)-(9), where two input parameters were used, the normalized pore distribution curve $f(r), \mathrm{R}_{\min }<\mathrm{r}$ $<\mathrm{R}_{\max }$, and the average value of moisture diffusivity $\kappa_{\mathrm{av}}$ determined in a common 


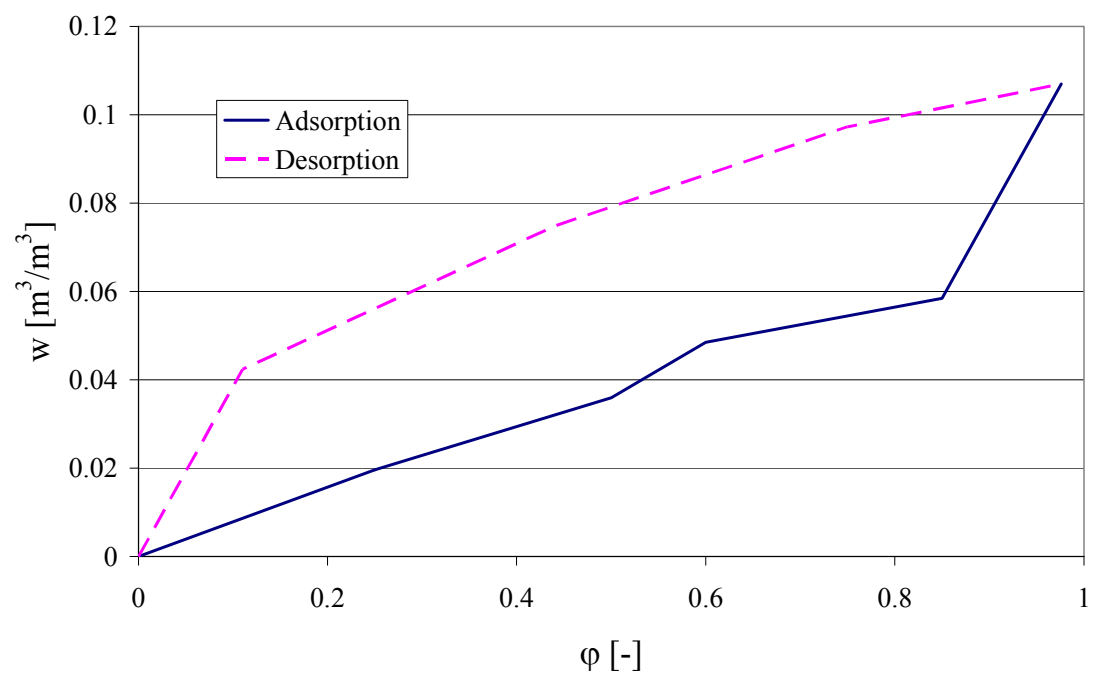

Figure 3: Sorption isotherm of concrete.

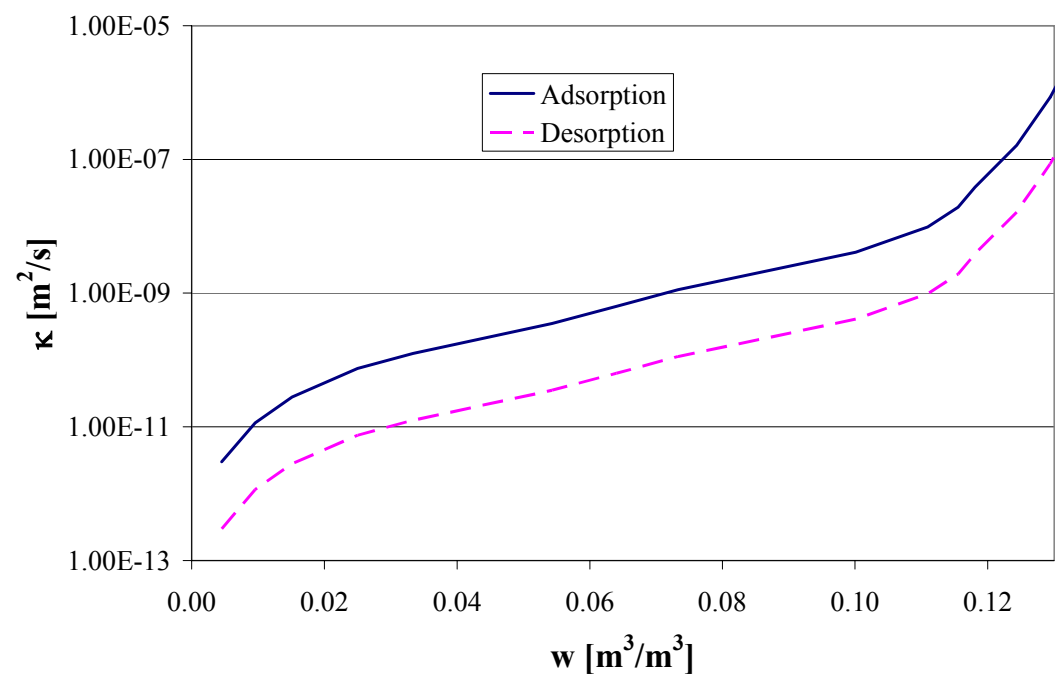

Figure 4: Moisture diffusivity of concrete.

sorptivity experiment [5], and the tortuosity effect was linearized for the sake of simplicity, i.e., an assumption of $n=1$ was adopted,

$$
\kappa_{r}(w)=\left(\frac{w}{w_{\text {sat }}}\right)^{n} \frac{R_{\mathrm{max}}^{2} f\left(R_{\max }\right)}{R^{2} f(R)} \frac{\int_{R_{\min }}^{R} r^{2} f(r) d r}{\int_{R_{\min }}^{R_{\max }} r^{2} f(r) d r},
$$




$$
\begin{array}{r}
\kappa\left(\frac{2}{3} w_{\text {sat }}\right)=\kappa_{a v} \\
w(R)=w_{\text {sat }} \int_{R_{\min }}^{R} f(r) d r
\end{array}
$$

Contrary to the sorption isotherms, where desorption curves can be obtained by common experimental techniques, the desorption curve of moisture diffusivity had to be set empirically as for its experimental determination no quite reliable techniques are available at present. Based on the results of experiments and computational analyses described in [6], it was estimated to be one order of magnitude lower than the adsorption curve.

The moisture transport and storage parameters of mineral wool insulation and exterior and interior plasters were assumed to be the same in both adsorption and desorption phase. The water vapor adsorption and moisture diffusivity of mineral wool are so low that hysteretic effects are within the error range of experimental methods in any case. The thickness of renders is much lower as compared to both concrete and mineral wool so that the effect of hysteresis in their hygric parameters on moisture transport in the wall as a whole is supposed to be neglected.
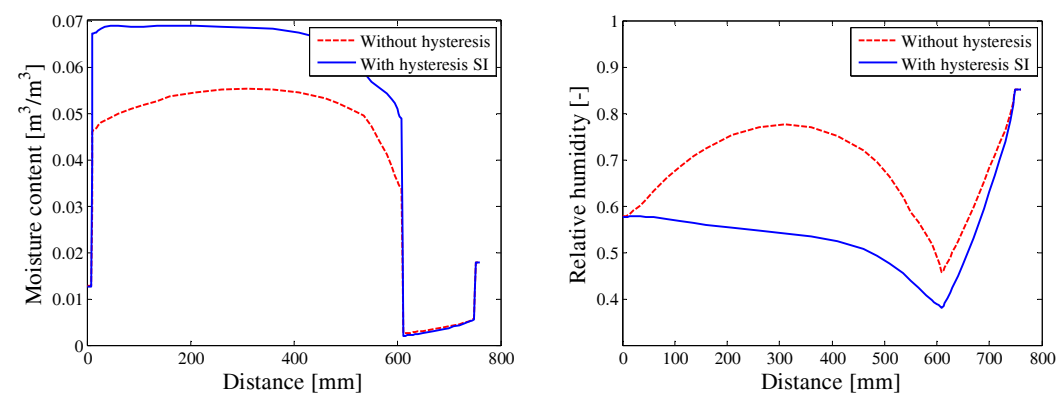

Figure 5: Moisture content (a) and relative humidity (b) profiles for January 1 .

\section{Results of computer simulations and discussion}

Three different simulations were performed, combining the effects of hysteresis of moisture transport and storage parameters, namely the simulation with hysteresis of sorption isotherm only, hysteresis of moisture diffusivity only and hysteresis of both sorption isotherm and moisture diffusivity. The calculations without hysteresis were done as well for the sake of comparison, using the data for adsorption phase which is usual in computational simulations where hysteresis is neglected. 


\subsection{Hysteresis of sorption isotherm}

Figs. 5(a), (b) show moisture content and relative humidity profiles calculated for January 1, which can be considered as characteristic for the winter period. The calculation with hysteretic effects led to increase of moisture content in the envelope, whereas relative humidity was significantly lower.

Figs. 6(a), (b) summarize the moisture and relative humidity fields during the whole simulated time period of 5 years calculated with hysteresis.
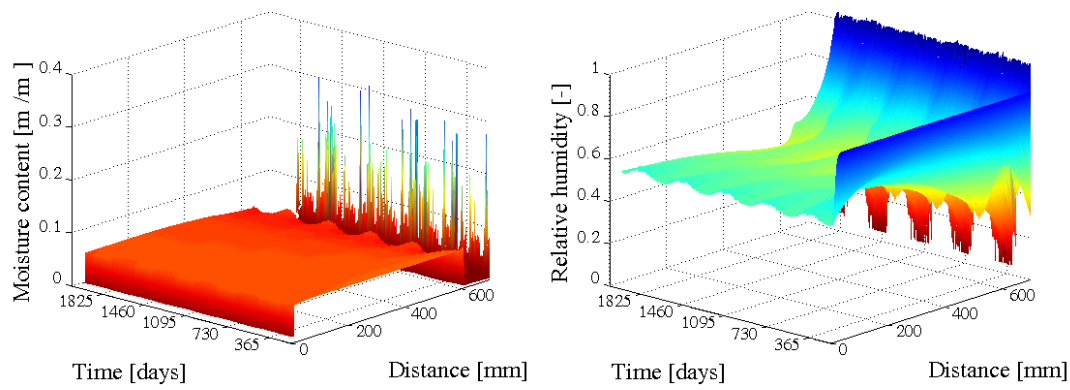

Figure 6: Moisture content (a) and relative humidity (b) fields during a 5 -year period.

\subsection{Hysteresis of moisture diffusivity}

The moisture and relative humidity profiles for January 1 (Figs. 7(a), (b)) show that both moisture content and relative humidity calculated with hysteresis were higher, which was a consequence of lower moisture diffusivity in drying phase.
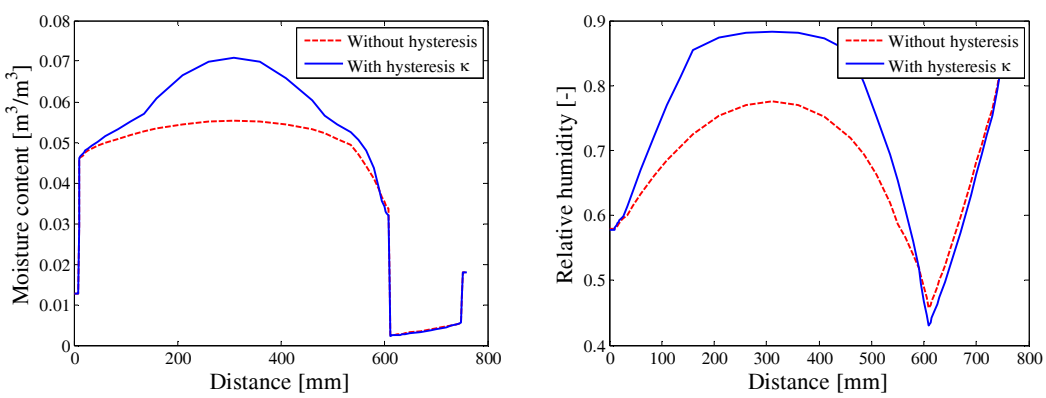

Figure 7: Moisture content (a) and relative humidity (b) profiles for January 1 .

Figs. 8(a), (b) show the moisture and relative humidity fields during the whole simulated time period of 5 years calculated with hysteresis. 

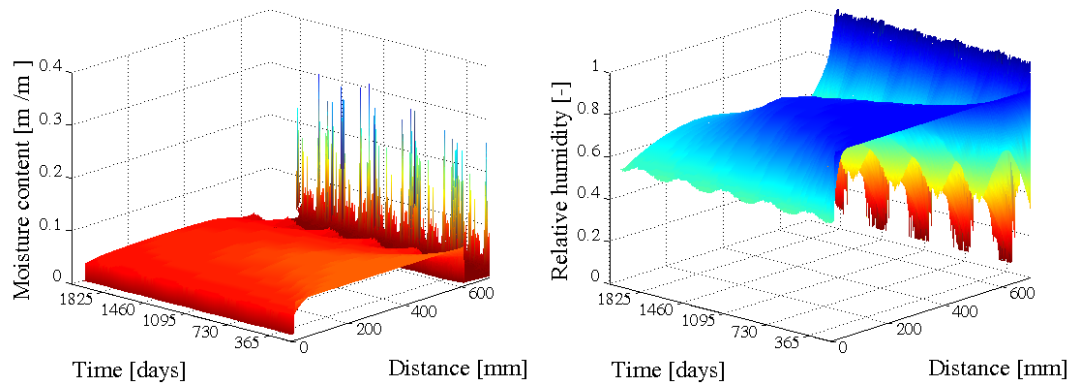

Figure 8: Moisture content (a) and relative humidity (b) fields during a 5 -year period.
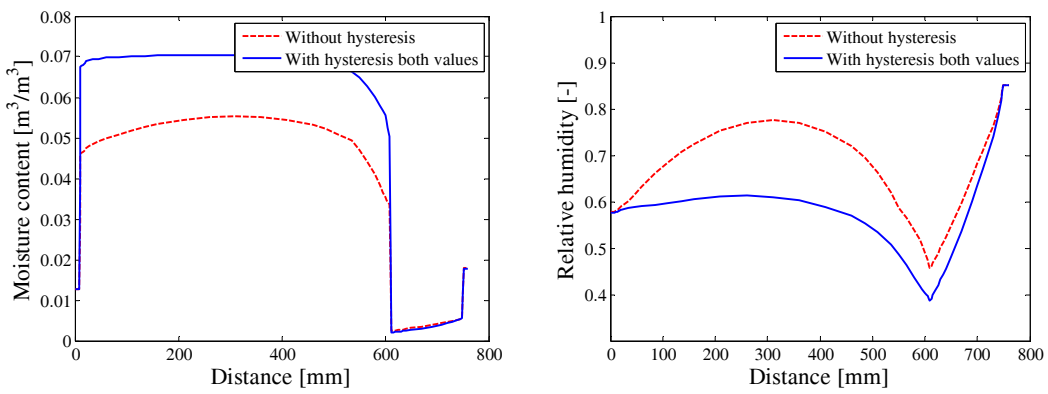

Figure 9: Moisture content (a) and relative humidity (b) profiles for January 1 .
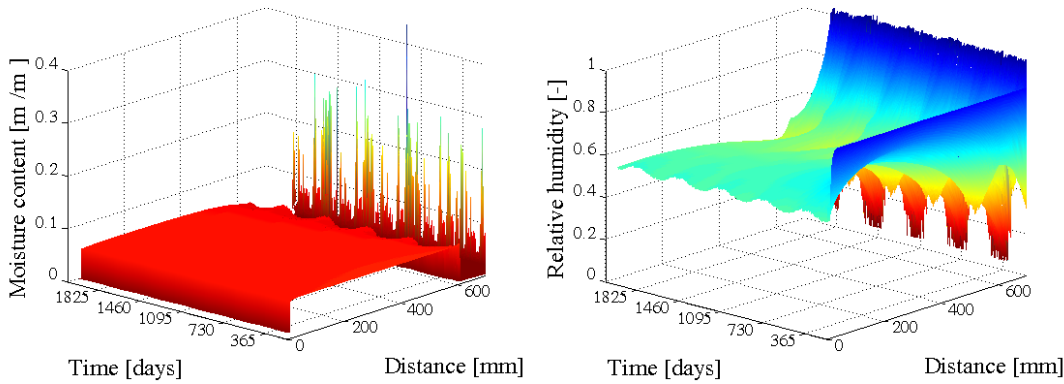

Figure 10: Moisture content (a) and relative humidity (b) fields during a 5 -year period.

\subsection{Hysteresis of both sorption isotherm and moisture diffusivity}

The moisture and relative humidity profiles (Figs. 9(a), (b)) were very similar to the simulations presented in 4.1 , which meant that the hysteretic effect of sorption isotherm had remarkably higher influence on simulation results. 
Figs. 10(a), (b) present the moisture and relative humidity fields during the whole simulated time period of 5 years calculated with hysteresis.
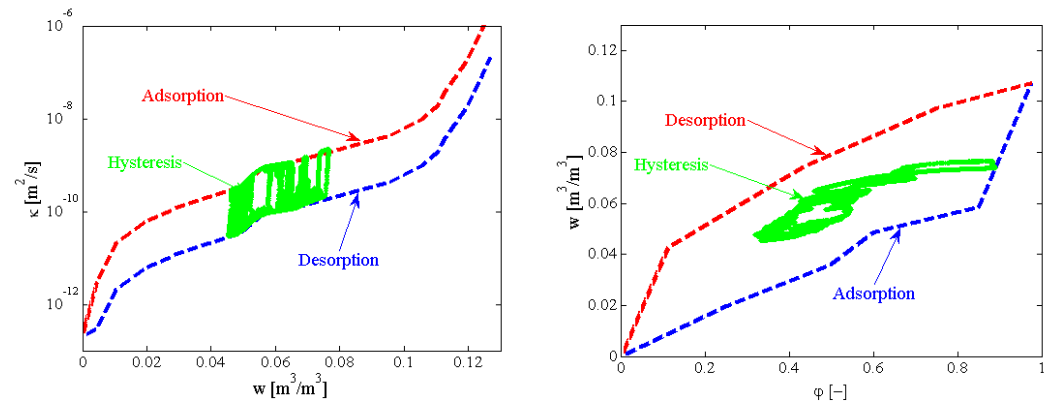

Figure 11: Calculation of hysteresis of moisture diffusivity (a) and sorption isotherm (b).

Figs. 11(a), (b) show how the hysteretic effects were manifested in the values of moisture diffusivity and sorption isotherm of concrete used by the model during the whole time period of 5-years simulation. While the water vapour sorption parameters were mostly near to the centerline of the area demarcated by the adsorption and desorption curves, the moisture diffusivities oscillated between the maximum and minimum values.
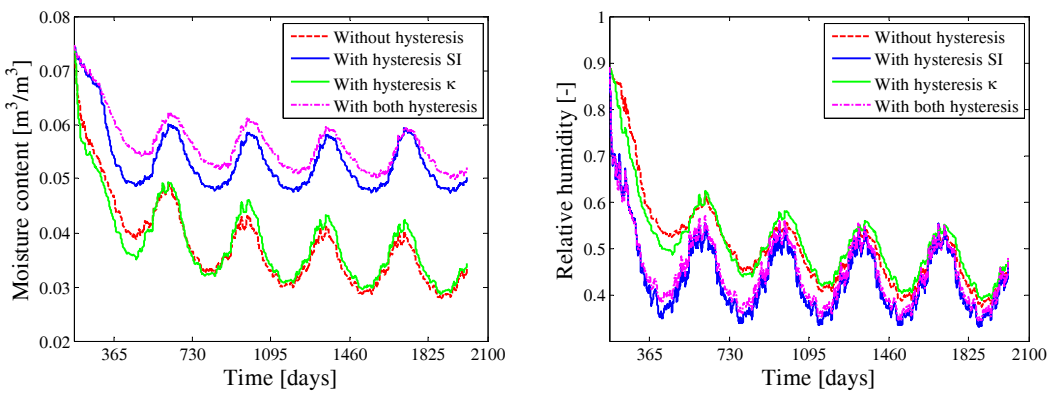

Figure 12: Moisture content (a) and relative humidity (b) in a characteristic locality in concrete, $1 \mathrm{~cm}$ from the interface between concrete and thermal insulation.

\subsection{Comparison of the effects of hysteresis of moisture transport and storage parameters}

Figs. 12(a), (b) present a comparison of the effects of hysteresis of moisture transport and storage parameters on moisture content and relative humidity for a characteristic locality in concrete, $1 \mathrm{~cm}$ from the interface between concrete and thermal insulation. As for the relative humidity profiles, it is obvious that all values came close each other in the $5^{\text {th }}$ year of simulation. Moisture content 
profiles were quite different. Results of simulation without hysteretic effect and with hysteresis of moisture diffusivity only were very similar, but they differed from the other simulations in a significant way. Besides, the yearly oscillations of water content were not steady yet after 5 years. Involving hysteretic effects of both moisture diffusivity and sorption isotherm caused the highest increase of moisture content in the chosen point. Similar results were also obtained for other points within the concrete part of the wall.

\section{Conclusions}

The computer simulations of coupled heat and moisture transport in this paper have shown that the application of hysteretic moisture transport and storage parameters can be considered as quite important in service life analyses of multilayered systems of porous building materials. The results indicated very significant differences in moisture and relative humidity profiles calculated using the model with hysteretic parameters and without hysteresis. As the differences were always on the dangerous side, it can be concluded that neglecting the hysteretic effects while desorption is in progress can lead to underestimation of damage risk due to water presence in a structure which is rather undesirable in any service life analysis.

\section{Acknowledgement}

This research has been supported by the Czech Science Foundation, under grant No 103/07/0034.

\section{References}

[1] Künzel, H. M., Simultaneous Heat and Moisture Transport in Building Components, $\mathrm{PhD}$ Thesis, IRB Verlag Stuttgart, 1995.

[2] Pedersen, C. R., Combined Heat and Moisture Transfer in Building Constructions, PhD Thesis, Report 214. Thermal Insulation Laboratory, TU Denmark, 1990.

[3] Vejmelková, E. \& Černý, R., Application of Alternative Silicate Binders in the Production of High Performance Materials Beneficial to The Environment. Proceedings of the 2008 World Sustainable Building Conference [CD-ROM]. Balnarring, Victoria: ASN Events Pty Ltd, 2008, p. 520-525, 2008.

[4] Pernicová, R., Pavlíková, M., Pavlík, Z. \& Černý, R., Vliv metakaolinu na mechanické, tepelné a vlhkostní vlastnosti vápenných omítek. Metakaolin 2007. Brno: VUT FAST, s. 70-77, 2007

[5] Černý, R. \& Rovnaníková, P., Transport Processes in Concrete, 1. ed. London: Spon Press, pp. 26-29, 2002.

[6] Pel L., Černý, R. \& Pavlík Z, Moisture and Ion Transport. WP5 2-Years Report of the EU 6th Program Project SSPI-CT-2003-501571. TU Eindhoven, Eindhoven, 2006. 